\title{
Influence of morbid obesity on physical capacity, knee-related symptoms and overall quality of life: A cross-sectional study
}

\author{
Lilian Sarl Tamura ${ }^{1}$, Everton Cazzo ${ }^{2 *}$, Elinton Adami Chaim ${ }^{3}$, Sérgio Rocha Piedade ${ }^{4}$ \\ ${ }^{1} \mathrm{MSc}$, Postgraduate Student, Department of Orthopedics and Traumatology, Faculdade de Ciências Médicas, Universidade Estadual de Campinas (Unicamp), Campinas, SP, Brazi \\ ${ }^{2} \mathrm{PhD}$, Assistant Lecturer, Department of Surgery, Faculdade de Ciências Médicas, Unicamp, Campinas, SP, Brazil \\ ${ }^{3}$ PhD, Full Professor, Department of Surgery, Faculdade de Ciências Médicas, Unicamp, Campinas, SP, Brazil \\ ${ }^{4}$ PhD, Full Professor, Department of Orthopedics and Traumatology, Faculdade de Ciências Médicas, Unicamp, Campinas, SP, Brazl
}

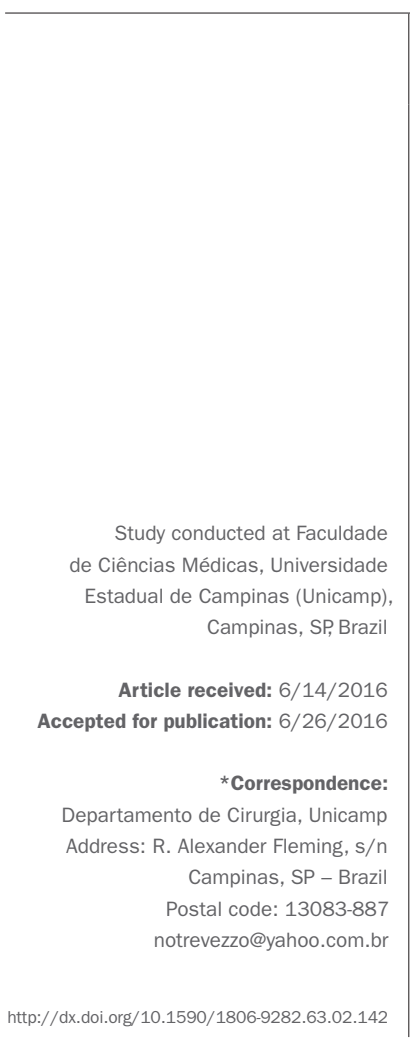

\section{SUMmARY}

Objective: To evaluate the impact of morbid obesity on physical capacity, joint-related symptoms, and on the overall quality of life.

Method: Cross-sectional study carried out at a university hospital, enrolling 39 individuals admitted to a bariatric surgery service. Physical capacity was assessed by Six-Minute Walk Test (SMWT) and the Borg rating of perceived exertion (RPE). Knee-related symptoms were evaluated by Knee Injury and Osteoarthritis Outcome Score (KOOS) and the Lysholm Score. Quality of life was evaluated by Short Form 36 Health Questionnaire (SF-36).

Results: On SMWT, the mean distance walked was $374.1 \pm 107.5 \mathrm{~m}$. The mean Borg score was $12.9 \pm 2.4$. KOOS questionnaire found the following scores: pain (64.3 \pm 24$)$, other symptoms $(67.2 \pm 25.5$ ), function in daily living (60.4 \pm 26.8$)$, function in sport and recreation (28.5 \pm 32.2$)$, knee-related quality of life (35.9 \pm 33.5$)$, mean Lysholm scale score (55.3 \pm 25.4$)$. SF-36 provided the following scores: physical functioning (41 \pm 27.4 ), physical role functioning (34.6 \pm 39.2$)$, bodily pain (45.7 \pm 23.6 ), general health perceptions $(63.1 \pm 26.2)$, vitality $(53.5 \pm 12.1)$, social role functioning

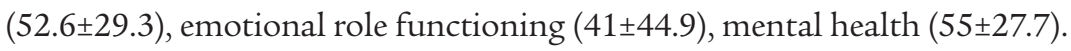

Conclusion: Obesity led to significant loss of physical capacity, gait impairment, knee-related symptoms, and a negative impact on the overall quality of life.

Keywords: obesity, quality of life, knee, joint diseases, arthralgia.

\section{INTRODUCTION}

Obesity is a medical disorder characterized by an abnormal accumulation of excess body fat, which is associated with adverse health effects. It has become a worldwide public health concern and, according to World Health Organization (WHO) reports, at least 2.8 million people each year die as a result of being overweight or obese. ${ }^{1}$

Along with diet, behavioral, and drug treatment strategies, physical activity plays a key role in the therapy of severe obesity. Most of the currently promoted exercise regimens include walking. However, recent evidence has shown a significant impairment in physical capacity associated with obesity, such as gait disturbances, posture deficits, and greater risk of falling. ${ }^{2-6}$ Furthermore, obesity presents a close relationship with chronic degenerative osteoarticular disease, which contributes even more to physical impairment and disability. ${ }^{46}$
There are a few studies evaluating functional abilities, physical capacity, and joint-related symptoms in morbidly obese individuals, as well as their impact on the overall quality of life.

\section{Objective}

This study sought to study the influence of morbid obesity on physical capacity, knee-related symptoms, as well as quality of life, in patients eligible for bariatric surgery.

\section{Method}

This is a cross-sectional study carried out at a university hospital, enrolling 39 individuals admitted to a bariatric surgery service from May to December, 2011.

Inclusion criteria were: body mass index (BMI) $\geq 40$ $\mathrm{kg} / \mathrm{m}^{2}$; age between 18 and 65 years old; capacity to understand the study design and provide informed consent. 
Exclusion criteria were: any physical disability not directly related with obesity; refusal to take part in the study; systemic diseases which could prevent the individual to perform the physical tests.

The variables evaluated were: age, gender, ethnic group, weight, BMI, age at onset of obesity, clinical condition, physical activity level, objective and subjective evaluation scores regarding knee-related symptoms, and quality of life.

Clinical condition was assessed based on heart rate, systolic and diastolic blood pressures, and respiratory rate. Patients were evaluated at rest and after physical exercise. Heart and respiratory rates were directly calculated by the researchers, and blood pressure was measured using an analogue calibrated sphygmomanometer.

To evaluate physical activity, the participants underwent a Six-Minute Walk Test (SMWT) and the Borg rating of perceived exertion. The Knee Injury and Osteoarthritis Outcome Score (KOOS) and Lysholm Score were used to assess symptoms related with the knees. The Short Form 36 Health Survey (SF-36) was used to assess quality of life. All of these scores and questionnaires have been previously validated. ${ }^{7-11}$

This study was assessed and approved by the local Research Ethics Board. All individuals provided informed consent. All of the forms and questionnaires were personally applied by the researchers.

\section{Six-Minute Walk Test (SMWT)}

The SMWT is a practical simple test that requires a $100-\mathrm{ft}$ hallway but no exercise equipment or advanced training for technicians. It evaluates the global and integrated responses of all the systems involved during exercise, including the pulmonary and cardiovascular systems, systemic circulation, peripheral circulation, blood, neuromuscular units, and muscle metabolism. Most patients do not achieve maximal exercise capacity during the SMWT; instead, they choose their own intensity of exercise and are allowed to stop and rest during the test. However, because most activities of daily living are performed at submaximal levels of exertion, the SMWT may better reflect the functional exercise level for daily physical activities. ${ }^{12}$

\section{Scale of Perceived Exertion (Borg scale)}

This is a psychophysiological scale that measures feelings of effort, strain, discomfort, and/or fatigue experienced during both aerobic and resistance training. The rating of perceived exertion (RPE) is often measured using a 15 category scale that was developed by Swedish psychologist
Gunnar Borg. It is a numerical scale that ranges from 6 to 20 , where 6 means "no exertion at all" and 20 means "maximal exertion.", 13

Knee Injury and Osteoarthritis Outcome Score (KOOS)

The KOOS is a self-administered questionnaire that includes five outcomes: pain, symptoms, activities of daily living, sport and recreation function, and knee-related quality of life. It was originally developed to assess shortand long-term patient-relevant outcomes following knee injury and arthritis. A 100-point score indicates absence of knee-related symptoms, while a 0 -point score reveals extreme knee-related symptoms. ${ }^{14}$

\section{Lysholm Score}

The Lysholm knee scale is a condition-specific outcome measure that was originally designed to assess ligament injuries of the knee. ${ }^{15}$ It encompasses eight questions, whose ultimate outcome is expressed nominally, that is "excellent" from 95 to 100 points; "good" from 84 to 94; "fair" from 65 to 83; and "poor" when below $65 .{ }^{16}$

\section{Short Form 36 Health Survey (SF-36)}

The SF-36 is a 36-item patient-reported survey of patient health. The SF-36 consists of eight scaled scores, which are the weighted sums of the questions in their section. Each scale is directly transformed into a 0-100 scale on the assumption that each question carries equal weight. A score of zero is equivalent to maximum disability and a score of 100 is equivalent to no disability. The eight sections are: vitality, physical functioning, bodily pain, general health perceptions, physical role functioning, emotional role functioning, social role functioning, and mental health. ${ }^{17}$

\section{Statistical analysis}

For comparison of categorical variables, we used Chi-square and Fischer's tests. To compare continuous measures, the Mann-Whitney test was used. The level of significance adopted was $5 \%(p<0.05)$. The statistical analyses were performed using the Statistical Package for Social Sciences (SPSS) software, version 16.0.

\section{Results}

Of 39 individuals, $84.6 \%$ were female. Mean age was $42.4 \pm 10.8$ years old. Regarding ethnic groups, $64.1 \%$ were White, $10.3 \%$ were Black, and $25.6 \%$ were mixed. Mean weight was $126.2 \pm 24.6 \mathrm{~kg}$; mean BMI was $49.4 \pm 6.8 \mathrm{~kg} / \mathrm{m}^{2}$. Table 1 summarizes the demographic and anthropometric characterizations of the population study. 
TABLE 1 Demographic and anthropometric

characteristics of the studied population.

\begin{tabular}{ll} 
Age (years) & $42.4 \pm 10.8$ \\
\hline Gender & Female: $33(84.6 \%)$ \\
& Male: $6(13.4 \%)$ \\
\hline Ethnic group & Whites: $25(64.1 \%)$ \\
& Blacks: $4(10.3 \%)$ \\
& Mixed: $10(25.6 \%)$ \\
\hline Weight $(\mathrm{kg})$ & $126.2 \pm 24.6$ \\
\hline BMI $\left(\mathrm{kg} / \mathrm{m}^{2}\right)$ & $49.4 \pm 6.8$ \\
\hline BMI: body mass index. &
\end{tabular}

Mean heart rate at rest was $73.1 \pm 14.3 \mathrm{bpm}$; after SMWT, it was $113.5 \pm 20.3 \mathrm{bpm}(\mathrm{p}<0.0001)$. Mean respiratory at rest was $19 \pm 4.9$ breaths per minute; after SMWT, it was $24.5 \pm 8.2$ breaths per minute $(\mathrm{p}=0.01)$. Mean systolic pressure at rest was $136.7 \pm 20.9 \mathrm{mmHg}$; after SMWT, it was $157 \pm 22.3 \mathrm{mmHg}(\mathrm{p}<0.0001)$. Mean diastolic pressure at rest was $95 \pm 16.7 \mathrm{mmHg}$; after SMWT, it was $91.4 \pm 15.7$ $\mathrm{mmHg}(\mathrm{p}=0.19)$. The SMWT yielded the following results: mean speed was $63.6 \pm 14.7 \mathrm{~m} / \mathrm{s}$; the mean distance walked was $374.1 \pm 107.5 \mathrm{~m}$. The mean Borg score was $12.9 \pm 2.4$. Table 2 shows the main findings regarding general clinical condition and the results of the SMWT and Borg scale.

Regarding joint-related symptoms, individuals reported pain in the ankles (7.7\%); knees (82.1\%); hips (23.1\%), and spine (48.7\%). Regarding therapies for pain, $76.9 \%$ reported more than weekly usage of analgesics and/or non-steroidal anti-inflammatory drugs (NSAIDs). Table 3 summarizes these findings.

The application of the KOOS questionnaire led to the following scores in each of the five subscales: pain: $64.3 \pm 24$; other symptoms: $67.2 \pm 25.5$; function in daily living: $60.4 \pm 26.8$; function in sport and recreation: $28.5 \pm 32.2$; knee-related quality of life: $35.9 \pm 33.5$. The mean Lysholm scale score was $55.3 \pm 25.4$. Table 4 details these findings.

Application of SF-36 survey provided the following scores in each section: physical functioning: $41 \pm 27.4$; physical role functioning: $34.6 \pm 39.2$; bodily pain: $45.7 \pm 23.6$; general health perceptions: $63.1 \pm 26.2$; vitality: $53.5 \pm 12.1$; social role functioning: $52.6 \pm 29.3$; emotional role functioning: $41 \pm 44.9$; mental health: $55 \pm 27.7$. Table 5 summarizes the SF-36 application results.

\section{Discussion}

Gait impairment in obese individuals exerts a significant impact on routine daily activities. We observed slow gait speed and consequently low distance walked on the SMWT. Comparing our SMWT results with those observed in healthy individuals by Ziegler et al. ${ }^{18}$ and Burr et al. ${ }^{19}$ we found lower distances walked. Pataky et al. ${ }^{6}$ reported that obese women tend to have slower gait speeds and accompanying shorter stride lengths, relatively less powerful lower limbs and a poorer endurance compared to lean individuals. Comparative studies by Dufek et al. ${ }^{20}$ and Hergenroeder et al. ${ }^{21}$ have also shown significantly slower speeds and distances in obese individuals. Thus, gait impairment observed in our results is comparable to previous reports. SMWT has considerable advantages, since it is easy to perform, reproducible, and inexpensive. While it

\begin{tabular}{|c|c|}
\hline \multirow[t]{3}{*}{ Heart rate $(\mathrm{bpm})$} & At rest: $73.1 \pm 14.3$ \\
\hline & After SMWT: $113.5 \pm 20.3$ \\
\hline & $(p<0.0001)$ \\
\hline \multirow[t]{3}{*}{ Respiratory rate (brpm) } & At rest: $19 \pm 4.9$ \\
\hline & After SMWT: $24.5 \pm 8.2$ \\
\hline & $(p=0.01)$ \\
\hline \multirow[t]{3}{*}{ Systolic blood pressure $(\mathrm{mmHg})$} & At rest: $136.7 \pm 20.9$ \\
\hline & After SMWT: $157 \pm 22.3$ \\
\hline & $(p<0.0001)$ \\
\hline \multirow[t]{3}{*}{ Diastolic blood pressure $(\mathrm{mmHg})$} & At rest: $95 \pm 16$ \\
\hline & After SMWT: $91.4 \pm 15.7$ \\
\hline & $(p=0.19)$ \\
\hline \multirow[t]{2}{*}{ SMWT results } & Speed $(\mathrm{m} / \mathrm{s}): 63.6 \pm 14.7$ \\
\hline & Distance $(\mathrm{m}): 374.1 \pm 107.5$ \\
\hline RPE (Borg) score & $12.9 \pm 2.4$ \\
\hline
\end{tabular}

bpm: beat per minute; brpm: breaths per minute; $\mathrm{mmHg}$ : millimeters of mercury; SMWT: sixminute walk test; RPE: rating of perceived exertion; $\mathrm{m} / \mathrm{s}$ : meters per second; $\mathrm{m}$ : meters.

TABLE 3 Distribution of joint-related pain in the studied population.

\begin{tabular}{ll} 
Knees & $32(82.1 \%)$ \\
\hline Ankles & $3(7.7 \%)$ \\
\hline Hips & $9(23.1 \%)$ \\
\hline Spine & $19(48.7 \%)$ \\
\hline Others & $4(10.2 \%)$ \\
\hline
\end{tabular}

TABLE 4 Results of the KOOS questionnaire and Lysholm score.

KOOS

Pain: $64.3 \pm 24$

Other symptoms: $67.2 \pm 25.5$

Function in daily living: $60.4 \pm 26.8$

Sport and recreation: $28.5 \pm 32.2$

Knee-related quality of life: $35.9 \pm 33.5$

Lysholm score $55.3 \pm 25.4$

KOOS: Knee Injury and Osteoarthritis Outcome Score. 
TABLE 5 Results of the SF-36 survey.

\begin{tabular}{ll} 
Physical functioning & $41 \pm 27.4$ \\
\hline Physical role functioning & $34.6 \pm 39.2$ \\
\hline Bodily pain & $45.7 \pm 23.6$ \\
\hline General health perceptions & $63.1 \pm 26.2$ \\
\hline Vitality & $53.5 \pm 12.1$ \\
\hline Social role functioning & $52.6 \pm 29.3$ \\
\hline Emotional role functioning & $41 \pm 44.9$ \\
\hline Mental health & $55 \pm 27.7$
\end{tabular}

reproduces the activity of daily living, it also has a good correlation with peak oxygen uptake obtained via cardiopulmonary exercise test. However, the test does not provide insight into the mechanisms of exercise limitation. ${ }^{22}$

Regarding the Borg scale, this study has shown a significant perception of exertion among our obese population studied. Ziegler et al. ${ }^{18}$ had observed lower values for this score among healthy individuals, with only $23.8 \%$ of the individuals achieving a score above 5 points; compared with the mean score of 12.9 in this study, it is reasonable to conclude that obesity has a significant impact on the perception of breathlessness. A meta-analysis that considered moderating variables such as sex, fitness level, psychological status, and mode of exercise showed that, although the validity of the scale of perceived exertion was not as high as originally reported, the relationships with physiological measures of exercise intensity remained high. ${ }^{13}$ However, it is not free of limitations, since Joo et al. ${ }^{23}$ reported that $80 \%$ of cardiac rehabilitation patients who were prescribed exercise at a rating of perceived exertion of 11 to 13 exercised at levels deemed to be unsafe.

Obesity is largely associated with physical impairment and joint diseases, and is currently recognized as an independent risk factor for knee osteoarthritis. ${ }^{6,24-26}$ This study found a high prevalence of joint pain, affecting mainly the knees. In a meta-analysis, obesity led to a nearly threefold increase in the risk of knee osteoarthritis. ${ }^{27}$ Obesity is related with these changes by means of two interconnected pathways: increased load caused by excessive weight, and systemic effects related with chronic inflammation linked to imbalance in the release of active peptides produced by the fat tissue known as adipocytokines. .2,28,29 $^{2}$ The assessment of knee-related symptoms using KOOS score in this study has shown impact mainly regarding pain and other symptoms compared with the mean values in non-obese individuals as reported in a systematic review by Collins et al..$^{30}$ In a prospective study, Edwards et al..$^{31}$ observed significant improvement in the five domains of
KOOS following weight loss, while Gudbergsen et al. ${ }^{32}$ reported improvement in pain and function in daily living domains after weight loss. Thus, the results observed in our study regarding the KOOS methodology were similar to those previously observed in the literature. The KOOS score has undergone a substantial amount of psychometric testing, largely among populations for whom the scale was intended. Establishment of the KOOS as a reliable and valid measure across multiple languages highlights its usefulness as a patient-reported measure of knee function. ${ }^{9,30}$ On the other hand, it also presents a few flaws, since it has not been validated for interview administration, meaning that it may not be appropriate for patients who are unable to read or write, or where telephone follow-up is necessary. Moreover, when administering the KOOS in older or less physically active individuals, the most physically demanding components of the activities of daily living (ADL) and sport/recreation subscales may not be applicable, and could result in missing data. ${ }^{30}$

The mean Lysholm score observed in this study was also considerably lower than that found in healthy individuals by Briggs et al. $(55.3 \pm 25.4$ versus $94 \pm 16.4) \cdot{ }^{33}$ This finding reinforces the impairment of knee function among our obese population. The Lysholm scale is a freely available measure that allows detection of changes following nonsurgical and surgical interventions. It is considered to have face validity by orthopedic surgeons. It also presents some flaws, because the items in the Lysholm scale are surgeon-derived, thus content validity from the patient's perspective cannot be assumed. The Lysholm scale was developed as a clinician-administered tool, which increases the potential for interviewer bias if the patient-reported outcome is applied as intended. ${ }^{30}$

We found a significantly negative overall impact of morbid obesity on quality of life assessed by the SF-36 compared to the results observed in the general population. Compared to the SF-36 scores achieved in Brazil in a study by Cruz et al., ${ }^{34}$ morbidly obese individuals presented significantly lower scores in all of the eight domains evaluated. Since obesity is strongly linked to several clinical comorbidities and also influences social-economical and psychological issues, this finding was expected. The results of the present study also signaled lower SF-36 scores than those observed in the general population in the United Kingdom. ${ }^{35-37}$ Despite its wide availability and applicability, the SF-36 has also received some criticism, especially due to the possible social disability bias observed when it is obtained by means of personal interview, mainly in the mental, emotional, and vitality domains. ${ }^{36}$ Moreover, the survey presents a low response rate in aged and 
cognitively impaired individuals. ${ }^{38}$ Nonetheless, its usage is currently widespread and it is considered a reliable tool to easily and objectively assess quality of life. ${ }^{39}$

This study has some limitations. First, the studied population was composed by a small number of individuals, which reduces the statistical impact of the results as well as does not make it possible to provide age and gender-related scores. Furthermore, since the study was not controlled, there was no possibility of comparison with a local matched population. The evaluation tools and questionnaires present the above cited limitations and caveats as well. Nonetheless, the findings in this study are still clearly indicative of the negative impact of obesity on physical functioning and overall quality of life. Further research, mainly in a controlled setting enrolling larger populations, is necessary to confirm these findings.

\section{Conclusion}

In our study, obesity led to significant loss of physical capacity, gait impairment, knee-related symptoms, and a negative impact on the overall quality of life.

\section{STATEMENT OF INFORMEd CONSENT}

Informed consent was obtained from all individual participants included in the study.

\section{StATEMENT OF HUMAN AND ANIMAL RIGHTS}

All procedures performed in studies involving human participants were in accordance with the ethical standards of the institutional and/or national research committee and with the 1964 Helsinki declaration and its later amendments or comparable ethical standards.

\section{Conflict of interest}

The authors declare no conflict of interest.

\section{Resumo}

Influência da obesidade mórbida sobre a capacidade física, sintomas relacionados aos joelhos e qualidade de vida geral: um estudo transversal

Objetivo: Avaliar o impacto da obesidade mórbida sobre a capacidade física, sintomas osteoarticulares e qualidade de vida global.

Método: Estudo transversal realizado em hospital universitário, envolvendo 39 indivíduos admitidos em um serviço de cirurgia bariátrica. A capacidade física foi avaliada através do teste de caminhada de 6 minutos e pela escala de percepção de esforço de Borg. Os sintomas relacionados ao joelho foram avaliados pelos escores de KOOS e Lysholm; a qualidade de vida foi avaliada por meio do questionário SF-36.

Resultados: No teste de caminhada de 6 minutos, a distância média foi de $374,1 \pm 107,5 \mathrm{~m}$. O escore médio de Borg foi $12,9 \pm 2,4$. Os seguintes escores foram observados no KOOS: dor $(64,3 \pm 24)$; outros sintomas $(67,2 \pm 25,5)$; atividades da vida diária $(60,4 \pm 26,8)$; atividades esportivas e lazer $(28,5 \pm 32,2)$; qualidade de vida $(35,9 \pm 33,5)$; o escore de Lysholm médio foi $55,3 \pm 25,4$. O SF-36 mostrou estes escores: capacidade funcional $(41 \pm 27,4)$; limitação por aspectos físicos $(34,6 \pm 39,2)$; dor $(45,7 \pm 23,6)$; estado geral de saúde $(63,1 \pm 26,2)$; vitalidade $(53,5 \pm 12,1)$; aspectos sociais $(52,6 \pm 29,3)$; aspectos emocionais $(41 \pm 44,9)$; saúde mental $(55 \pm 27,7)$.

Conclusão: A obesidade levou à perda significativa de capacidade física, a prejuízo à marcha, a sintomas relacionados ao joelho e a impacto negativo sobre a qualidade de vida global.

Palavras-chave: obesidade, qualidade de vida, joelho, artropatias, artralgia.

\section{References}

1. World Health Organization (WHO). Global status report on noncommunicable diseases 2014. Geneva: WHO; 2014.

2. Wanigatunga AA, Sourdet SS, LaMonte MJ, Waring ME, Nassir R, Garcia L, et al. Physical impairment and body weight history in postmenopausal women: the Women's Health Initiative. Public Health Nutr. 2016; 19(17):3169-77.

3. Germain CM, Batsis JA, Vasquez E, McQuoid DR. Muscle strength, physi cal activity, and functional limitations in older adults with central obesity. J Aging Res. 2016; 2016:8387324.

4. Madigan M, Rosenblatt NJ, Grabiner MD. Obesity as a factor contributing to falls by older adults. Curr Obes Rep. 2014; 3(3):348-54.

5. Lang IA, Llewellyn DJ, Alexander K, Melzer D. Obesity, physical function, and mortality in older adults. J Am Geriatr Soc. 2008; 56(8):1474-8.

6. Pataky Z, Armand S, Müller-Pinget S, Golay A, Allet L. Effects of obesity on functional capacity. Obesity (Silver Spring). 2014; 22(1):56-62.

7. Du H, Newton PJ, Salamonson Y, Carrieri-Kohlman VL, Davidson PM. A review of the six-minute walk test: its implication as a self-administered assessment tool. Eur J Cardiovasc Nurs. 2009; 8(1):2-8.

8. Borg G, Ljunggren G, Ceci R. The increase of perceived exertion, aches and pain in the legs, heart rate and blood lactate during exercise on a bicycle ergometer. Eur J Appl Physiol Occup Physiol. 1985; 54(4):343-9.

9. Roos EM, Lohmander LS. The Knee injury and Osteoarthritis Outcome Score (KOOS): from joint injury to osteoarthritis. Health Qual Life Outcomes. 2003; 1:64.

10. Tegner $Y$, Lysholm J. Rating systems in the evaluation of knee ligament in juries. Clin Orthop Relat Res. 1985; (198):43-9.

11. Brazier JE, Harper R, Jones NM, O'Cathain A, Thomas KJ, Usherwood T, et al. Validating the SF-36 health survey questionnaire: new outcome measure for primary care. BMJ. 1992; 305(6846):160-4.

12. ATS Committee on Proficiency Standards for Clinical Pulmonary Function Laboratories. ATS statement: guidelines for the six-minute walk test. Am J Respir Crit Care Med. 2002; 166(1):111-7.

13. Chen MJ, Fan X, Moe ST. Criterion-related validity of the Borg ratings of perceived exertion scale in healthy individuals: a meta-analysis. J Sports Sci. 2002; 20(11):873-99. 
14. Roos EM, Roos HP, Lohmander LS, Ekdahl C, Beynnon BD. Knee Injury and Osteoarthritis Outcome Score (KOOS) - development of a self-administered outcome measure. J Orthop Sports Phys Ther. 1998; 28(2):88-96.

15. Kocher MS, Steadman JR, Briggs KK, Sterett WI, Hawkins RJ. Reliability, validity, and responsiveness of the Lysholm knee scale for various chondral disorders of the knee. J Bone Joint Surg Am. 2004; 86-A(6):1139-45.

16. Peccin MS, Ciconelli R, Cohen M. Questionário específico para sintomas do joelho "Lysholm Knee Scoring Scale": tradução e validação para a língua portuguesa. Acta Ortop Bras. 2006; 14(5):268-72.

17. Laucis NC, Hays RD, Bhattacharyya T. Scoring the SF-36 in Orthopaedics: a brief guide. J Bone Joint Surg Am. 2015; 97(19):1628-34.

18. Ziegler B, Fernandes AK, Sanches PR, Konzen GL, Dalcin PT. Variability of the perception of dyspnea in healthy subjects assessed through inspiratory resistive loading. J Bras Pneumol. 2015; 41(2):143-50.

19. Burr JF, Bredin SS, Faktor MD, Warburton DE. The 6-minute walk test as a predictor of objectively measured aerobic fitness in healthy working-aged adults. Phys Sportsmed. 2011; 39(2):133-9.

20. Dufek JS, Currie RL, Gouws PL, Candela L, Gutierrez AP, Mercer JA, et al Effects of overweight and obesity on walking characteristics in adolescents. Hum Mov Sci. 2012; 31(4):897-906.

21. Hergenroeder AL, Brach JS, Otto AD, Sparto PJ, Jakicic JM. The influence of body mass index on self-report and performance-based measures of physical function in adult women. Cardiopulm Phys Ther J. 2011;22(3):11-20.

22. Heresi GA, Dweik RA. Strengths and limitations of the six-minute-walk test: a model biomarker study in idiopathic pulmonary fibrosis. Am J Respir Crit Care Med. 2011; 183(9):1122-4.

23. Joo KC, Brubaker PH, MacDougall A, Saikin AM, Ross JH, Whaley MH. Exercise prescription using resting heart rate plus 20 or perceived exertion in cardiac rehabilitation. J Cardiopulm Rehabil. 2004; 24(3):178-84; quiz 185-6.

24. Koonce RC, Bravman JT. Obesity and osteoarthritis: more than just wear and tear. J Am Acad Orthop Surg. 2013; 21(3):161-9.

25. Manek NJ, Hart D, Spector TD, MacGregor AJ. The association of body mass index and osteoarthritis of the knee joint: an examination of genetic and environmental influences. Arthritis Rheum. 2003; 48(4):1024-9.

26. Workgroup of the American Association of Hip and Knee Surgeons Evidence Based Committee. Obesity and total joint arthroplasty: a literature based review. J Arthroplasty. 2013; 28(5):714-21.

27. Blagojevic M, Jinks C, Jeffery A, Jordan KP. Risk factors for onset of osteoarthritis of the knee in older adults: a systematic review and meta-analysis. Osteoarthritis Cartilage. 2010; 18(1):24-33
28. Sowers MR, Karvonen-Gutierrez CA. The evolving role of obesity in knee osteoarthritis. Curr Opin Rheumatol. 2010; 22(5):533-7.

29. Plotnikoff R, Karunamuni N, Lytvyak E, Penfold C, Schopflocher D, Imayama I, et al. Osteoarthritis prevalence and modifiable factors: a population study. BMC Public Health. 2015; 15:1195.

30. Collins NJ, Prinsen CA, Christensen R, Bartels EM, Terwee CB, Roos EM Knee Injury and Osteoarthritis Outcome Score (KOOS): systematic review and meta-analysis of measurement properties. Osteoarthritis Cartilage. 2016; 24(8):1317-29.

31. Edwards C, Rogers A, Lynch S, Pylawka T, Silvis M, Chinchilli V, et al. The effects of bariatric surgery weight loss on knee pain in patients with osteoarthritis of the knee. Arthritis. 2012; 2012:504189.

32. Gudbergsen H, Boesen M, Lohmander LS, Christensen R, Henriksen M, Bartels EM, et al. Weight loss is effective for symptomatic relief in obese subjects with knee osteoarthritis independently of joint damage severity assessed by high-field MRI and radiography. Osteoarthritis Cartilage. 2012; 20(6):495-502.

33. Briggs KK, Steadman JR, Hay CJ, Hines SL. Lysholm score and Tegner activity level in individuals with normal knees. Am J Sports Med. 2009; 37(5):898-901.

34. Cruz LN, Fleck MP, Oliveira MR, Camey SA, Hoffmann JF, Bagattini AM, et al. Health-related quality of life in Brazil: normative data for the SF-36 in a general population sample in the south of the country. Cien Saude Colet. $2013 ; 18(7): 1911-21$.

35. Burholt V, Nash P. Short Form 36 (SF-36) Health Survey Questionnaire: normative data for Wales. J Public Health (Oxf). 2011; 33(4):587-603.

36. Bowling A, Bond M, Jenkinson C, Lamping DL. Short Form 36 (SF-36) Health Survey questionnaire: which normative data should be used? Comparisons between the norms provided by the Omnibus Survey in Britain, the Health Survey for England and the Oxford Healthy Life Survey. J Public Health Med. 1999; 21(3):255-70.

37. Jenkinson C, Coulter A, Wright L. Short form 36 (SF 36) health survey questionnaire: normative data for adults of working age. BMJ. 1993; 306(6890): $1437-40$

38. Andresen EM, Gravitt GW, Aydelotte ME, Podgorski CA. Limitations of the SF-36 in a sample of nursing home residents. Age Ageing. 1999; 28(6):562-6.

39. Barile JP, Horner-Johnson W, Krahn G, Zack M, Miranda D, DeMichele K, et al. Measurement characteristics for two health-related quality of life measures in older adults: the SF-36 and the CDC Healthy Days items. Disabil 